\title{
ESTUDO DE CASO: RECONSTITUIÇÃO DE EVENTOS DEPOSICIONAIS FLUVIAIS EM TRECHO DO RIBEIRÃO DO CHIQUEIRO, GOUVEIA - MG
}

\author{
Glaucia Silva Oliveira ${ }^{(a)}$ \\ (a) Instituto de Geociências, Universidade Federal de Minas Gerais, e-mail: glau.gaia@gmail.com
}

Eixo: GEOCRONOLOGIA E ESTUDOS PALEOAMBIENTAIS

\begin{abstract}
Resumo/
Este documento (com margens de 2,5cm) respeita o formato que os artigos submetidos deverão ter, podendo ser utilizado para a edição final do texto A bacia do córrego do Chiqueiro corresponde a uma depressão com sentido N-S em área localizada na "Depressão Gouveia", sendo circundada, em todas as direções pelas Escarpas quartzíticas da Serra do Espinhaço que delimitam dois compartimentos geomorfológicos distintos: o piso da depressão e a superfície de cimeira (Saadi e Valadão, 1987). Já foram desenvolvidos estudos relativos aos níveis deposicionais no referido córrego e procurou-se com este trabalho complementar com novas informações sobre as sequências sedimentares incorporadas no córrego chiqueiro. Foram encontrados quatro níveis deposicionais no recorte espacial estudado no Ribeirão do Chiqueiro: um terraço, uma planície e dois níveis deposicionais sem forma definida. A hipótese levantada, que justifica a migração lateral do rio, está ligada à neotectônica. Pois houve o soerguimento da Serra do Juá, tal fato provocou o basculamento do bloco localizado a margem direita do ribeirão, formando assim um hemi-gráben. O ribeirão Chiqueiro tende ao encaixamento na base da Serra do Juá.

Palavras- Chave: Níveis deposicionais, ribeirão Chiqueiro, terraços.
\end{abstract}

\section{INTRODUÇÃO}

A Geomorfologia corresponde ao estudo das formas de relevo e de seus agentes, materiais e processos formadores. Por sua vez, a Geomorfologia Fluvial dedica-se à compreensão da contribuição fluvial na esculturação das paisagens. Nesse sentido os cursos d'água se constituem em importantes elementos esculturadores do relevo: eles atuam nos processos denudacionais e sedimentares por meio da erosão de seu leito e carreamento desses sedimentos gerados ao longo de toda a bacia de drenagem. Na evolução da paisagem, impulsionada pela contribuição fluvial, são construídas formas de relevo, tais como terraços e planícies aluviais, que guardam, em seus sedimentos, informações sobre o contexto e o regime sedimentológico ao qual o rio esteve exposto quando de sua deposição (BARROS, 2012). Dessa forma, o estudo dos terraços e das planícies aluviais possibilita a compreensão dos eventos morfodinâmicos de uma área, uma vez que constituem em registros/ respostas de eventos deposicionais, denudacionais exogenéticos e endogenéticos (SOMMÉ 1990 apud BARROS, 2012). 
As planícies de inundação correspondem a uma feição geomorfológica, relativamente plana, que bordeja um rio e que é inundada periodicamente com a elevação do nível da água durante a estação chuvosa do ano (LEOPOLD et al., 1964 apud BARROS, 2012). Dessa forma, o conceito está ligado, primeiramente, a variável morfológica, embora associe-se também ao componente hidrológico do rio a qual faz parte, uma vez que está relacionada à atividade atual do curso d'água, por ser uma área inundada periodicamente. É importante ressaltar ainda que, por ser uma zona de atividade constante e periódica do rio, a planície de inundação é caracterizada pela presença de sedimentos inconsolidados (RITTER et al., 2002 apud BARROS, 2012). Por fim, resta acrescentar que ela é formada pela combinação de processos de sedimentação dentro do canal e nas margens (KINGSTON et al. apud BARROS, 2012).

Por sua vez, o terraço fluvial também corresponde a uma forma, relativamente plana, encontrada nas porções marginais dos cursos d'água e que "guardam" sedimentos outrora transportados pelo mesmo. Dessa forma, ele é formado basicamente por duas partes: a superfície plana, que representa a superfície da planície original, e uma escarpa, que é o declive que conecta a superfície do terraço a qualquer outra superfície inferior no vale (BARROS, 2012).

Os terraços resultam do encaixamento gradual do rio, resultante da erosão de seu leito, quando ele passa a dominar sobre o processo de agradação (que dá origem às planícies de inundação). A dominância do processo de encaixamento faz com que a planície seja dissecada, restando dela apenas algumas porções que se configuram em terraços fluviais. É devido a tal processo que, normalmente, os terraços são considerados planícies de inundação abandonadas, isto é, que não fazem parte mais da dinâmica atual do rio (BRIDGE, 2003; JACOBSON et al., 2003; LEOPOLD et al., 1964; RITTER et al., 2002; SCHUMM, 1977 apud BARROS, 2012). Entretanto, nem todos os terraços correspondem a planícies abandonadas e muitas vezes eles não conservam sua forma plana, característica essencial para a adoção do termo terraço. Neste caso, opta-se pelo termo níveis deposicionais fluviais ou seqüências deposicionais fluviais.

Posto isso, é importante acrescentar que os estudos sobre níveis e seqüencias deposicionais fluviais representam um dos núcleos mais importantes da Geomorfologia Fluvial já que fornecem informações para a reconstituição de eventos paleomofodinâmicos (BARROS e MAGALHÃES JÚNIOR, 2009). Tal possibilidade de reconstituição relaciona-se ao fato de as seqüencias de terraços e/ ou níveis deposicionais constituírem-se em registros da ocorrência de uma série de fatores pretéritos, em escala regional e continental, tais como flutuações climáticas, atividade neotectônica e mudanças do nível de base. Entretanto, em alguns casos, esses fatores não são perceptíveis em escala local, destacando-se assim a atuação dos níveis de base locais e soleiras na configuração de terraços e/ou níveis deposicionais (CHEETHAM et al., 2010). De qualquer forma, independente do fator de formação de um nível deposicional, a presença do mesmo pressupõe uma mudança significativa das condições predominantes 
durante a formação da superfície plana (período de estabilidade) e daquelas que produziram a escarpa (BARROS, 2012). Mesmo quando a forma do terraço não é preservada, o abandono de um nível deposicional pela dinâmica atual do rio pressupõe mudança nas condições paleoambientais (clima, neotectônica, nível de base, entre outras) regionais ou locais. As condições paleoambientais de formação de terraços e/ou níveis deposicionais, condicionam também os tipos de configuração dos mesmos. Dessa forma, os níveis deposicionais podem ser classificados em pareados ou isolados encaixados ou escalonados.

As tipologias pareado e isolado dizem respeito a existência ou não de um mesmo nível deposicional em ambas as margens de um curso d'água. Dessa forma, um nível deposicional é tido como pareado quando são encontrados, em mesma cota altimétrica, seus registros sedimentares fluviais em ambas as margens de um rio. São formados, portanto, por um amplo aplainamento seguido de uma rápida incisão vertical. Por outro lado, os níveis deposicionais isolados são aqueles em que os seus registros sedimentares não apresentam mesma cota altimétrica nas duas margens de um curso d'água, tendo sido formados por uma incisão vertical sincrônica à migração lateral (BARROS, 2012).

Já as tipologias escalonado e embutido referem-se à relação topográfica de um nível deposicional mais jovem com o nível deposicional imediatamente anterior (CHRISTOFOLETTI, 1981). Em ambos os tipos, o processo é o mesmo: após um período longo de incisão e migração lateral, de abertura do vale, o curso d'água passa por um momento relativamente mais rápido de incisão vertical, abandonando o nível deposicional que estava sendo construído. Entretanto, no caso dos níveis deposicionais escalonados, a incisão vertical é suficientemente intensa para expor o substrato rochoso, denotando portanto, um input de energia acentuado para a formação do mesmo, o que é geralmente atribuído a causas neotectônicas. Por outro lado, os níveis deposicionais encaixados (ou embutidos) são aqueles em que a incisão vertical não é suficientemente intensa para expor o substrato rochoso. Nesse caso, são formados por meio de uma sucessão de fases com regimes hidrossedimentológicos distintos, sem que haja incisão no substrato entre eles. Em geral, a formação de níveis deposicionais embutidos está relacionada à perda de energia do sistema fluvial que pode ter como causas capturas fluviais, oscilações climáticas ou mesmo soerguimento do nível de base loca (BARROS, 2012).

Essa revisão teórica acerca de planícies de inundação e terraços (ou níveis deposicionais) faz-se necessária na medida em que o estudo dessas formas, como anteriormente explicitado, constituem em um dos núcleos mais importantes da Geomorfologia Fluvial. Tendo em vista a relevância do estudo dessas formas para a compreensão paleoambiental fluvial, bem como, em última instância, no entendimento da contribuição fluvial na evolução da paisagem, o que se pretende como objetivo geral da presente pesquisa é, com base em níveis e sequencias deposicionais fluviais, reconstituir os eventos deposicionais do Vale 
do Ribeirão do Chiqueiro, situado na Depressão de Gouveia (Serra do Espinhaço), Minas Gerais. Desta forma, propõe-se como objetivos específicos deste trabalho, primeiramente, identificar e caracterizar os níveis deposicionais e seqüências sedimentares fluviais no Vale do Ribeirão do Chiqueiro. Posteriormente buscar-se-á relacioná-los aos possíveis eventos deposicionais e paleoambientais atuantes durante a deposição de cada um desses níveis e seqüencias sedimentares fluviais. Por fim, pretende-se, com o cumprimento desses dois objetivos, contribuir para a avanço dos conhecimentos geomorfológicos fluviais na Depressão de Gouveia (MG).

A presente pesquisa, bem como a escolha da área de estudo, se justifica pela lacuna de estudos no âmbito da Geomorfologia Fluvial em zonas continentais. Essa preferência pelos ambientes litorâneos deve-se ao fato deles apresentarem uma maior continuidade dos registros sedimentares, enquanto que nos ambientes continentais esses registros, não raro, apresentam-se de forma descontínua, distribuídos de forma irregular nas diversas formas de relevo (MOURA, 1994 apud BARROS e MAGALHÃES JÚNIOR, 2012). Além disso, os principais estudos em ambientes continentais no Brasil dedicam-se aos rios de grandes dimensões como o Amazonas, Araguaia e Paraná, sendo ainda mais raros os estudos em maior escala e em cursos d'água de áreas montanhosas. Em Minas Gerais alguns cursos d'água com essas características (bacias de menor porte e em áreas montanhosas) já foram estudados na região do Quadrilátero Ferrífero (BARROS e MAGALHÃES JÚNIOR, 2012; BARROS, 2012; MAGALHÃES JUNIOR et al., 2012; SANTOS et al., 2008; BARROS e MAGALHÃES JÚNIOR, 2009), mas os cursos d'água na região da Serra do Espinhaço ainda merecem mais atenção. É o caso do Ribeirão do Chiqueiro que encontra-se na Depressão de Gouveia, Serra do Espinhaço Meridional, onde afloram-se, circundados pelos quartzitos do Supergupo Espinhaço, granitos e gnaisses do Complexo Gouveia (ver caracterização da área de estudo). Dessa forma, além da carência de estudos na região do Espinhaço Meridional, a escolha do Ribeirão do Chiqueiro como lócus de pesquisa se justifica também pelo contexto litológico singular da região. Assim, um estudo nos níveis deposicionais e sequiencias sedimentares na região pode fornecer pistas sobre o contexto paleoambiental na Depressão de Gouveia, contribuindo para o avanço dos conhecimentos da Geomorfologia Fluvial em áreas montanhosas, de diversidade litólogica e contexto geológico singular.

\section{PROCEDIMENTOS METODOLÓGICOS}

A proposta deste trabalho foi de se realizar um estudo na área de Geomorfologia Fluvial no Vale do Ribeirão do Chiqueiro A escolha do local foi feita com base em imagens de satélite do Google Earth 2016, ao longo de um trecho do Ribeirão do Chiqueiro (ver caracterização da área de estudo). Os fatores observados para a escolha dos locais onde seriam efetuados os estudos foram: acessibilidade ao curso d'água, anomalias de drenagem (trechos retilíneos, curvas acentuadas e fora de contexto) e contexto 
geomorfológico (relação do curso d'água com o relevo). Essa etapa constitui a etapa de gabinete do trabalho.

No mês de março de 2016 foi realizada uma visita de campo no trecho do Ribeirão do Chiqueiro selecionado na etapa de gabinete. Para a realização da etapa prática da presente pesquisa, foram identificados os níveis e sequencias sedimentares fluviais ao longo do trecho do rio. Em seguida foram levantados dados de perfis aluviais a partir de seções verticais e da observação do contexto espacial dos depósitos. Na descrição dos níveis deposicionais e sequencias sedimentares fluviais, buscou-se destacar: a tipologia do nível encontrado (pareado ou isolado, e, escalonado ou embutido); sua posição em relação ao curso fluvial atual, em especial, desnível e distância dos depósitos em relação ao mesmo; altitude; composição granulométrica, espessura, organização e contato (abrupto ou gradual) entre as fácies. No caso das fácies de cascalho, foi determinada a presença ou não de matriz, o tamanho médio, a litologia e o grau de arredondamento dos mesmos. Foi observada ainda em campo a presença ou não de estruturas sedimentares, cimentação ferruginosa, matéria orgânica e bioturbação.

Com os dados de todos os grupos em mãos, os níveis deposicionais foram identificados por meio da relação entre dados de altitude e desnível para o rio atual, distância em relação ao curso d'água e características das sequencias sedimentares identificadas. Após a identificação dos níveis, estes foram representados em perfis estratigráficos (para caracterização de seus sedimentos) e perfis longitudinal e transversal, que possibilitam uma visão mais contextualizada das condições ambientais do trecho do Ribeirão do Chiqueiro. Os perfis estratigráficos correspondem a perfis-síntese, isto é, uma junção de vários perfis que constituem um mesmo nível deposicional, representando, portanto um sumário de todas as seções relativas a certo nível deposicional.

Dentre o conjunto de perfis aluviais de cada nível deposicional levantado em campo, um perfil mais representativo foi escolhido, com vistas a coleta de amostras para análise granulométrica no laboratório de geomorfologia do IGC/ UFMG. Os testes de laboratório foram realizados em maio de 2016.

Após a sistematização dos dados, buscaram-se reconstituir, com base nas características dos níveis deposicionais identificados, os eventos deposicionais que ocasionaram a sedimentação de cada um desses níveis. Para tanto, foram destacados possíveis condicionantes neotectônicos, climáticos e mudanças de nível de base, para subsidiar a análise dos eventos deposicionais.

\section{3. ÁREA DE ESTUDO}

A bacia do Córrego do Chiqueiro integra parte do território municipal de Gouveia que está localizado na grande unidade morfoestrutural da Serra do Espinhaço entre os paralelos $18^{\circ} 20^{\prime}-18^{\circ} 30 \mathrm{~S}$, e os meridianos 


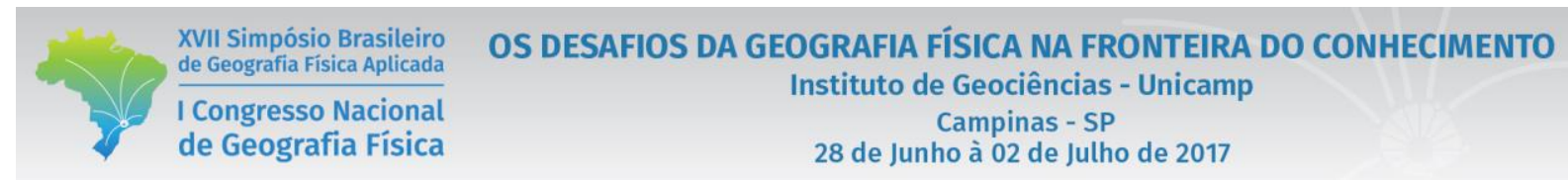

$43^{\circ} 40^{\prime}-43^{\circ} 50^{\prime} \mathrm{W}$, ocupa a porção centro-norte do Estado de Minas Gerais, distante quase $250 \mathrm{~km}$ de Belo Horizonte (MAPA 1).

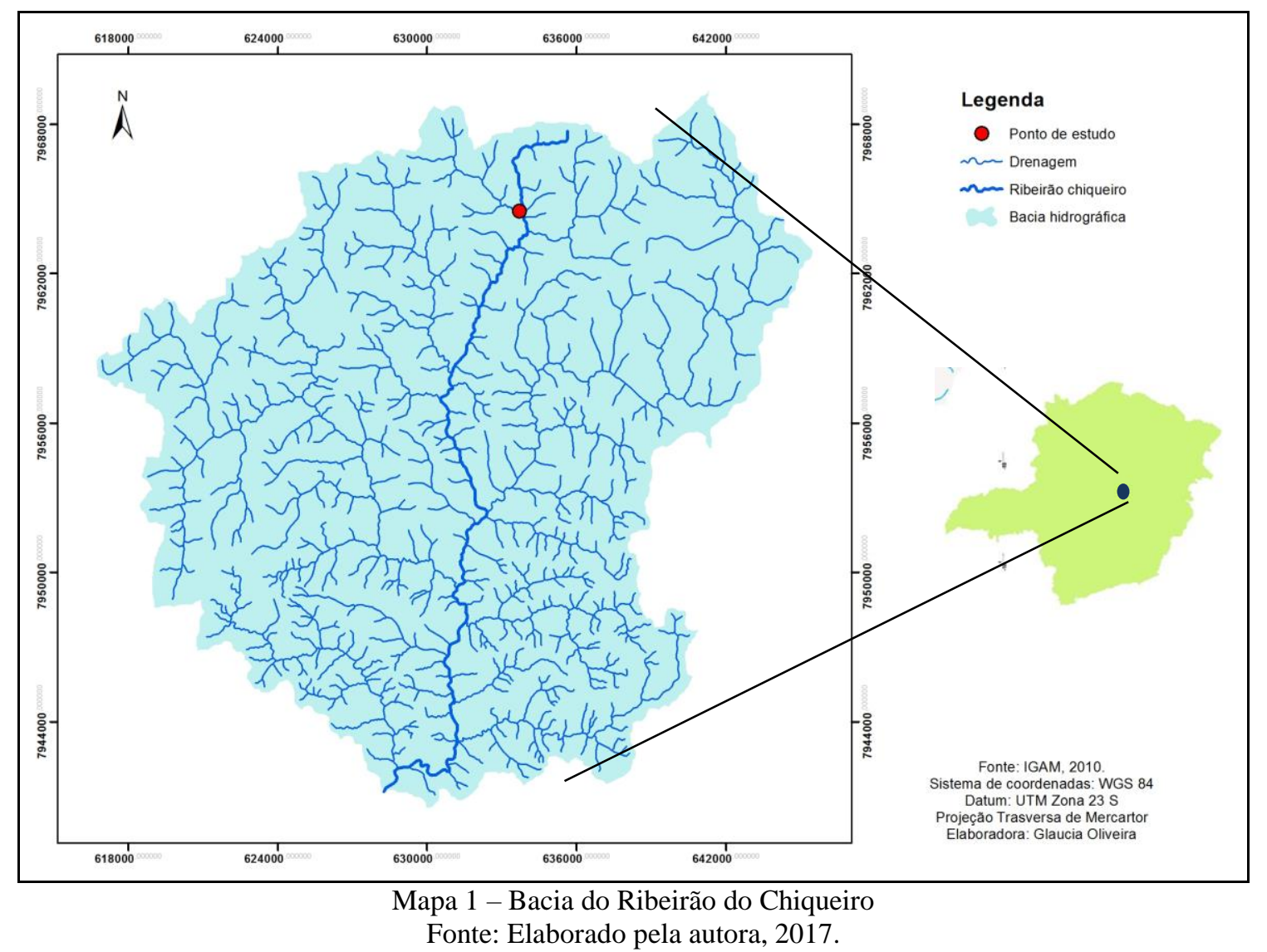

Segundo Augustin (1995), Saadi e Valadão (1987), a bacia do córrego do Chiqueiro corresponde a uma depressão com sentido N-S, que se originou do intemperismo e da erosão local dos três grandes grupos litológicos: o Complexo Basal, o Supergrupo Rio Paraúna e os metassedimentos proterozóicos do Supergrupo Espinhaço, que conformavam um antigo anticlinório localizado na área (MAPA 2).

A área que correspondente a "Depressão Gouveia" é circundada, em todas as direções pelas Escarpas quartzíticas da Serra do Espinhaço. De acordo com Salgado e Valadão (2005) essas escarpas delimitam dois compartimentos geomorfológicos distintos: o piso da depressão e a superfície de cimeira. Entende-se por piso da depressão as áreas geomorfologicamente modeladas nas rochas do embasamento arqueano, geologicamente denominado Complexo Gouveia, onde predominam granitos e gnaisses, com ocorrências de intrusão Metabásicas do Proterozóico, cujo relevo é composto por colinas suavizadas e interflúvios alongados com altitudes que podem variar de 1000 a 1050. Há nessa área uma intensa dissecação fluvial comandada pelos Ribeirões do Chiqueiro e da Areia. Já a superfície de cimeira compreende os substratos 
onde predominam os quartzitos do Supergrupo Espinhaço e que se apresentam na paisagem como relevos residuais que se elevam a mais de $1.400 \mathrm{~m}$ de altitude.

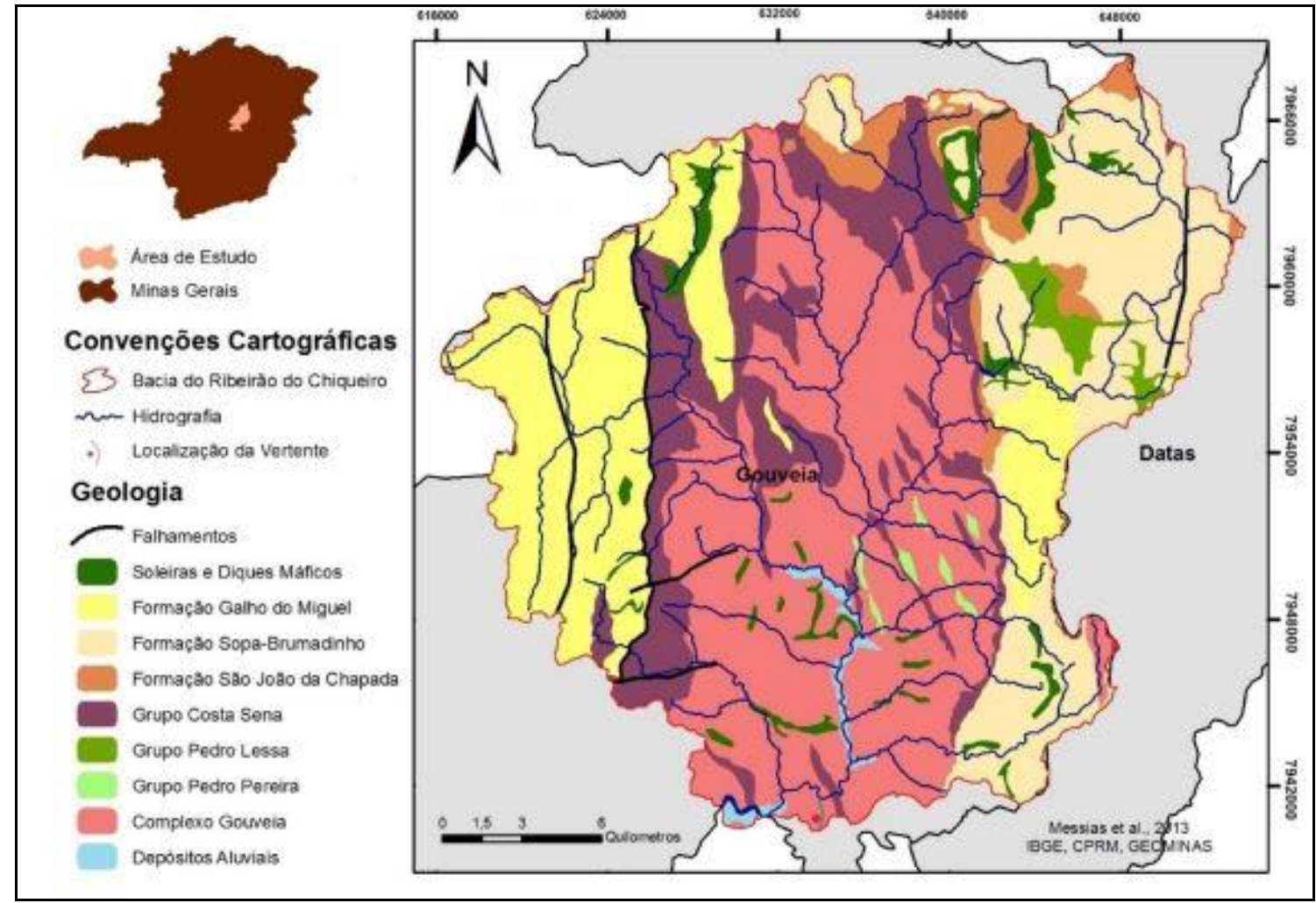

Mapa 2- Geológico da Bacia do Ribeirão Chiqueiro.

Fonte: MARTINS, R. M.; AMORIM, M. A. F.; AUGUSTIN, C. H. R. R.; AZEVEDO, P. A.A., 2013.

O clima na área estudada corresponde ao tropical semi-úmido com duas estações bem definidas: seca no inverno (que vai de maio a setembro) e úmida no verão (de agosto a abril). Com vegetação típica de cerrado nas áreas mais baixas, e campos de altitudes nos topos mais elevadas. Em Gouveia tem-se o predomínio dos processos desnudacionais geoquímicos, em decorrência principalmente à litologia presente, que pode ser facilmente identificado nas numerosas voçorocas encontradas na área.

\section{NÍVEIS DEPOSICIONAIS}

Foram identificados quatro níveis deposicionais no recorte espacial estudado no Ribeirão do Chiqueiro: um terraço, uma planície e dois níveis deposicionais sem forma definida (FIGURA 1). Começando pelos mais recentes, temos o nível um (N1), este correspondente a uma base fóssil de sedimentos recobertos pela planície de inundação, caracterizada como parelhada. O nível dois (N2) ainda conserva parte das suas características originais, podendo ser observado na margem direita uma superfície horizontal escarpada, 


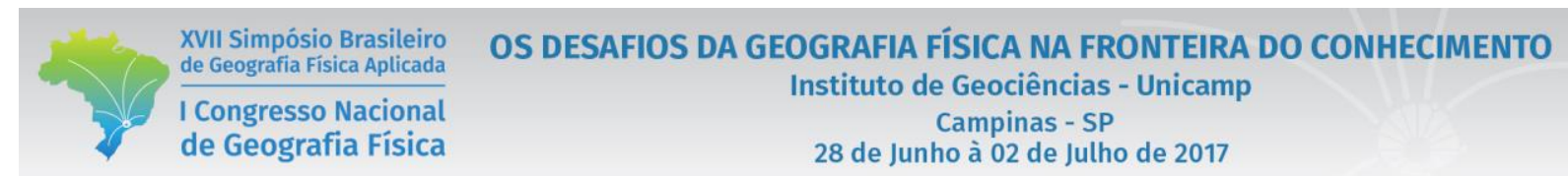

caracterizando assim um terraço isolado (T1). O nível três (N3), localizado na margem esquerda, devido a ação dos agentes desnudacionais e intempéricos, já não possuí suas formas bem definidas. O nível quatro (N4), situado na porção direita do curso d'água, é uma grande rampa de colúvio semi-embutido, pode-se observar neste nível uma intensa mobilização dos seixos por meio da ação antrópica possivelmente da atividade de garimpo ou ainda a retirada de rochas para calçamento. Tal fato é comum em Minas Gerais, uma vez que a destruição de terraços ou níveis deposicionais, no intuito de extrair minerais com grande valor de mercado, no caso de Gouveia, ouro e diamante, ou calçamento de estradas com seixos, foi uma prática usual. Estes níveis estão localizados em um trecho do Ribeirão do Chiqueiro bastante sinuoso, chegando em alguns pontos a meandrar. Apenas o N4 está semi-embutido no N2, onde os outros três níveis são escalonados.

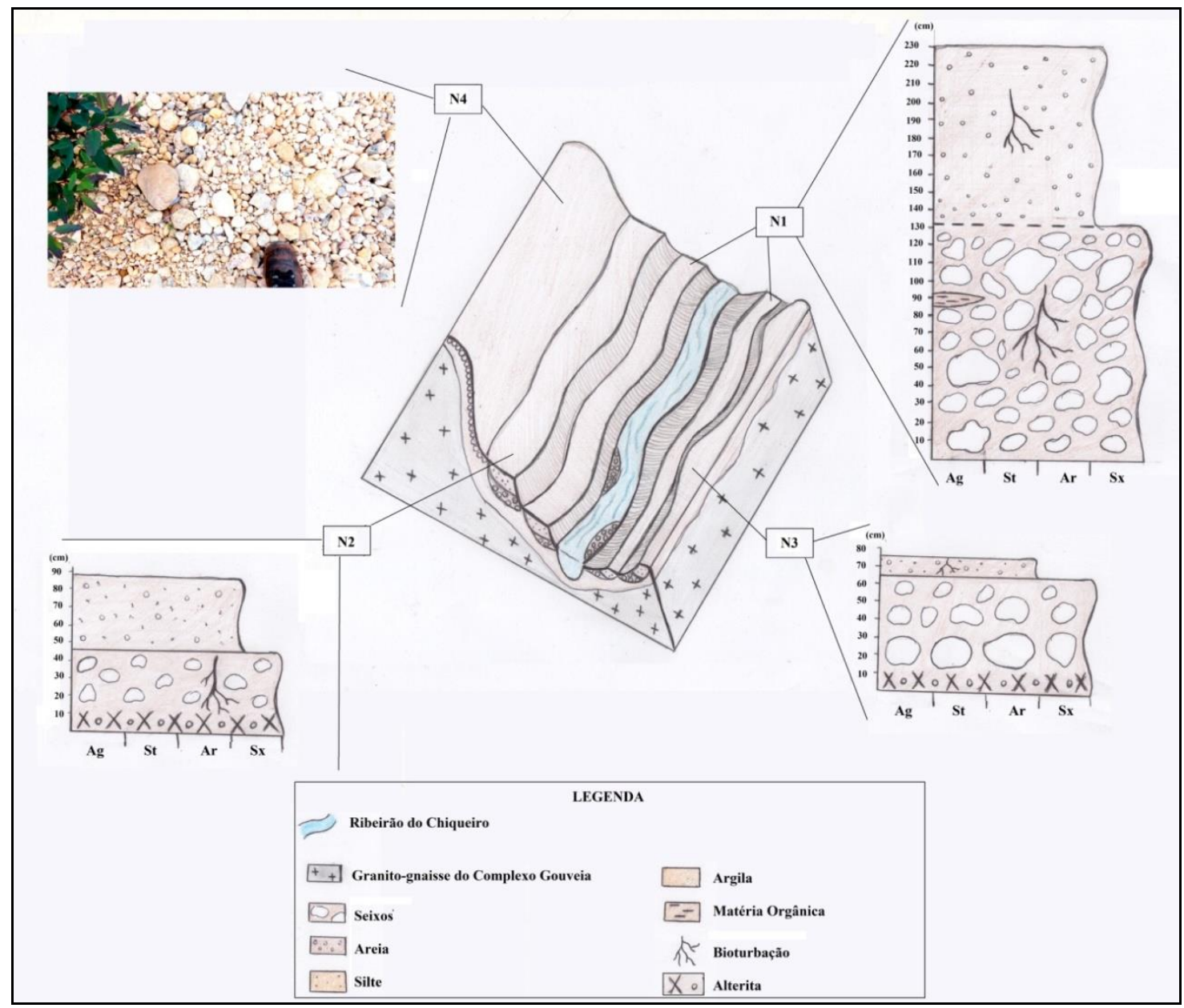

Figura 1: Bloco diagrama dos depósitos aluvionais. Fonte: Elaborado pela autora.

Tanto no leito menor quanto no leito vazante deste trecho do Ribeirão Chiqueiro, observa-se uma grande quantidade de seixos de diferentes tamanhos (desde seixos acima de $30 \mathrm{~cm}$ à seixos menores que $1 \mathrm{~cm}$ ) e de 
diferentes formas (seixos arredondados, subangulosos e seixos angulosos). A diferença no formato dos seixos pode estar ligada, dentre outros motivos, à proximidade com a fonte e a propriamente a área fonte. Constatamos o processo de encouraçamento dos seixos, tal processo ajuda na formação de vários níveis de base local, favorecendo na dinâmica de poço/corredeira bastante comum ao longo do trecho estudado. As barras de canal são um outro elemento recorrente no ribeirão, elas seguem o desenho do curso d'água, ou seja, retira sedimentos da margem côncava e deposita na margem convexa. Há também a presença de ilhas e mata de galeria.

O N1 é uma planície que está recobrindo uma base fóssil de seixos parelhada, sendo o seu perfil estratigráfico possui 2.30 metros de espessura. Com relação a granulometria deste nível, vemos duas fácies bastante marcadas: a base que é predominantemente de seixos e o topo que é constituído principalmente de areia. A parte inferior do perfil possuí 1,30 de altura, com a predominância de seixos, variando de tamanho $(2 \mathrm{~cm}$ à $25 \mathrm{~cm})$. Caracterizando-o pela forma dos seixos, temos formatos variados, como seixos subangulosos, subarredondados e arredondados. Temos também uma lente de matéria orgânica de aproximadamente $10 \mathrm{~cm}$ e a presença de bioturbação. A parte superior do perfil tem 1 metro de altura, ela é constituída principalmente por areia, havendo também a presença de bioturbação.

Ao analisar o perfil estratigráfico do N2 (terraço escalonado e isolado (T1), assim como na planície, identificamos duas fácies bem definidas. Este terraço tem uma altura de $90 \mathrm{~cm}$, sendo que sua base é constituída de alterita e acima desta, temos uma camada de seixos subarredondados com a espessura de $45 \mathrm{~cm}$, contendo também a presença de bioturbação. Já na parte superior do perfil, temos uma camada arenosiltosa de $45 \mathrm{~cm}$.

O perfil estratigráfico $\mathrm{N} 3$ possuí a espessura de $65 \mathrm{~cm}$, contendo duas fácies suportadas pela alterita. Logo acima da rocha intemperizada, vemos uma camada com $55 \mathrm{~cm}$ de espessura, esta é formada por seixos subarredondados de aproximadamente $10 \mathrm{~cm}$, onde se observa o processo de bioturbação. A camada da parte superior do perfil possuí $10 \mathrm{~cm}$ de espessura, sendo composta por partículas arenossiltosa e pelo processo de bioturbação.

A rampa de material aluvionar que representa o N4 está semi-embutida no N2, pode-se observar neste nível uma intensa mobilização dos seixos por meio da ação antrópica, os seixos são de tamanhos e formas variadas.

\section{DISCUSSÃO DOS RESULTADOS}

A hipótese levantada, que justifica a migração lateral do rio, está ligada à neotectônica. Pois houve o soerguimento da Serra do Juá, tal fato provocou o basculamento do bloco localizado na margem direita do 


\section{OS DESAFIOS DA GEOGRAFIA FÍSICA NA FRONTEIRA DO CONHECIMENTO \\ Instituto de Geociências - Unicamp \\ Campinas - SP \\ 28 de Junho à 02 de Julho de 2017}

ribeirão, formando assim um hemi-gráben. Então a tendência do Ribeirão do Chiqueiro foi de encaixar na base da Serra do Juá.

O basculamento do bloco provocou a migração lateral do Ribeirão do Chiqueiro em direção a margem esquerda, tal fato aconteceu de uma maneira rápida, por causa do hemi-gráben, assim o rio foi migrando lateralmente e deixando registros sedimentares fluviais. Como a migração foi de caráter rápido, o curso d'água não conseguiu escavar a superfície a ponto de deixar terraços bem formados, em que um dos testemunhos desta época é uma grande rampa de material aluvionar (N4) com seixos de diferentes tamanhos e formas. Estas evidências levaram à inferir que uma das características climáticas da época era um regime pluvial intenso, onde o rio possuía energia capaz de transportar sedimentos de granulometria média à grande.

O ribeirão continuou migrando e se encaixando em direção à atual margem esquerda até encontrar a base da Serra do Juá, que funcionou como barreira ao movimento de migração lateral do curso d'água. Dessa forma, o ribeirão sofreu incisão vertical de seu leito, por meio de processos erosivos fluviais, formando um terraço que hoje, após ser erodido, corresponde ao nível deposicional N3.

Após abandonar o nível deposicional N3, o Ribeirão do Chiqueiro passou a migrar lateralmente para a sua atual margem direita. Neste processo, foi depositando seixos de grande a médio porte em sua calha, onde em períodos de cheia do ribeirão foi depositado sedimentos finos acima dos seixos, formando assim o T1 (N2). Isto ocorreu num espaço de tempo maior do que o N4, uma vez que o T1 tem a forma de terraço bem definida (superfície horizontal e escarpa).

Após abandonar o T1 (N2), o ribeirão continuou migrando lateralmente para a margem esquerda e encaixando seu leito até chegar em sua posição atual no vale, formando o N1. No passado, quando o N1 estava sendo formado, ele tinha uma maior competência e seixos maiores eram transportados em seu leito. Uma das hipóteses levantadas é que nesta região, o clima continha um regime pluviométrico alto, no entanto com a mudança climática ocorrida, a quantidade de água existente no sistema diminuiu, e consequentemente houve a perda da competência de transportar seixos maiores. Disto resulta a atual configuração do ribeirão onde, no seu período de cheia, são depositados sedimentos finos em cima dos seixos deixados em épocas passadas (período em que o ribeirão possuía maior competência), o que caracteriza este depósito recente como uma planície de inundação de base fóssil (N1). Essa perda de competência em termos de dinâmica atual do Ribeirão do Chiqueiro, condiciona o encouraçamento, uma vez que os seixos são muito grandes para transporte atual, impedindo o rio de migrar lateralmente. Seria interessante um trabalho para conformar ou excluir a hipótese de que a perda de competência do rio teria sido motivada por mudanças climáticas. 


\section{REFERÊNCIAS BIBLIOGRÁFICAS}

BARRoS, L. F. P. Eventos Sedimentares do Quaternário e Evolução Morfodinâmica do Vale do Rio Conceição - Quadrilátero Ferrífero/MG. Dissertação de Mestrado. Departamento de Geografia, UFMG. Belo Horizonte, 2012.

BARros, L. F. P.; MAGAlHÃES JR, A. P. Eventos Sedimentares e Evolução Morfodinãmica do Vale do Rio Conceição - Quadrilátero Ferrífero/ MG. Revista Brasileira de Geomorfologia. º3. V.13. 2012. Disponível em: < http://www.ugb.org.br/home/?pg=10> Data de Acesso: 28/04/2014.

BARROS, L. F. P.; MAGALHÃES JR, A.P. Paleoambientes Deposicionais Fluviais e Dinâmica Atual do Vale do Rio Maracujá - Quadrilátero Ferrífero /MG. XVIII Simpósio Brasileiro de Recursos Hídricos. Campo Grande, MS. Novembro de 2009.

BUEnO, G. T.; TRINDADE, E. S.; MAGAlHÃES JR, A. P. Paleociclos Deposicionais e a Moderna Dinâmica Fluvial do Ribeirão do Chiqueiro, Depressão de Gouveia/Espinhaço Meridional - MG. Revista Geonomos, v.5 n. 2. 1997.

CHEETHAM, M. D.; BUSH, R.T.; KEENE, A.F.; ERSKINE, W.D. Nonsynchronous, episodicincision: Evidenceofthreshoudexceedanceandcomlex response as controlsofterraceformation. Geomofhology. 123.2010. p.320-329.

CHRISTOFOLETTI, A. Geomorfologia Fluvial. São Paulo: Blucher. 1981.

DINIZ, A. D; OLIVEIRA, C. D.; AUGUSTIN, C. H. R. R. Relações Solos - Superfícies Geomórficas na Porção Norte da Bacia do Ribeirão Chiqueiro, Gouveia, MG. Revista Geonomos - v.13 n. 1 e 2. 2005.

MARTINS, R. M.; AMORIM, M. A. F.; AUGUSTIN, C. H. R. R.; AZEVEDO, P. A. A Relação Entre Forma da Vertente, Cobertura Superficial e Sítios Geomorfológicos na Bacia do Ribeirão do Chiqueiro, Depressão de Gouveia, Serra do Espinhaço Meridional - MG. Revista Geonomos - v.21, n.2. 2013.

SALGADO, A. A. R.; VALADÃO. R. C. Fatores Controladores dos Processos Desnudacionais Geoquímicos no Espinhaço Meridional (Depressão de Gouveia, MG). Revista Geonomos - v.13 n. 1 e 2. 2005.

SANTOS et. al. Níveis e Seqüências Deposicionais Fluviais no Vale do Alto Rio das Velhas - Quadrilátero Ferrífero/ MG. Revista Geografias. Belo Horizonte, MG. N4. V.1. Julho-Dezembro de 2008. 